\title{
Ethnobotanical Studies of Medicinal Plants used to Treat Human and Livestock Ailments in Southern Nations, Nationalities and Peoples' Region, Ethiopia: A Systematic Review
}

\author{
Firew Bekele Abebe ${ }^{1}$ \\ ${ }^{1}$ College of Agriculture and Environmental Sciences, School of Natural Resources Management, Haramaya \\ University, Ethiopia \\ Correspondence: Firew Bekele Abebe, School of Natural Resources Management and Environmental Sciences, \\ College of Agriculture and Environmental Sciences, Haramaya University, Ethiopia. Tel: 251-912-490-990. \\ E-mail: firewb12@gmail.com
}

Received: November 14, 2018

Accepted: December 30, 2018 Online Published: January 25, 2019

doi:10.5539/jps.v8n1p1

URL: https://doi.org/10.5539/jps.v8n1p1

\begin{abstract}
Like many other parts of Ethiopia, people in the Southern Nations, Nationalities and Peoples' Region (SNNPR) do have indigenous knowledge on the preparation and use of traditional medicinal plants. Even though different studies have been conducted to document medicinal plants in different zones of SNNPR separately, there is no previous review work which summarizes the medicinal plants and the associated indigenous knowledge at the regional level (at SNNPR region as a whole or in large scale). Also, there is no previous review work that prioritizes the factors that affect medicinal plants at the regional level (including threatened medicinal plants). The purpose of this paper was to review habitat, growth forms, the method of remedy preparation and administration, marketability of medicinal plants, and to prioritize the factors that affect medicinal plants in SNNPR. Most of the medicinal plants in the majority of the reviewed areas are harvested from wild. Herbs are the most utilized life forms and leaves are the most utilized plant part in the preparation of remedies. Fresh plant materials are the most employed in the preparation of remedies. Majority of medicinal plants are not marketable. Agricultural land expansion is a major threat to medicinal plants which followed by deforestation. Olea europaea subsp. cuspidata, Prunus africana, Echinops kebericho, Croton macrostachys, Cordia africana and Dodonaea angustifolia, Hagenia abyssinica, Withania somnifera and Ficus spp are the highly affected medicinal plant species which require conservation and management priority in the region.
\end{abstract}

Keywords: conservation, growth form, habitat, indigenous knowledge, management medicinal plants, remedy, threat

\section{Introduction}

Starting from early times plants have been important sources of both defensive and curative traditional medicine preparations for both human beings and livestock. Native people around the world have exceptional knowledge of plant resources on which they depend for medicine and other uses (Martin, 1995). According to Farnsworth (1994), much of an indigenous knowledge system from the earliest times is found linked with the use of traditional medicine in different countries.

Ethiopia is a country characterized by a wide range of ecological, edaphic, and climatic conditions. As a result of its wide range of ecological, edaphic and climate diversity, is an important regional center for biological diversity (Kelbessa et al., 1992; Teketay, 2001; Friis et al., 2011) and possesses a wide range of potentially useful medicinal plants, more extensive indeed than available in many other parts of the world (Abebe, 1986; Pankhurst, 2001; Yirga, 2010). This wide potential has been made reachable by a rich biodiversity and an ancient indigenous knowledge on the use of plants in traditional medicine (Balemie et al., 2004), on which $80 \%$ of the rural communities in the country depend (Addis et al., 2001; Bekalo et al., 2009; Birhan et al., 2018). Even in cities where modern health services are more available and specialized; numerous people still continue to go to traditional healers for their primary healthcare requirements (Lambert, 2001; Mesfin et al., 2009). Incomplete coverage of the modern medical system, lack of pharmaceuticals, poor staffing and expensive prices of modern drugs (Zerabruk and Yirga, 2012; Hishe and Asfaw, 2015) can be reasons why the majority of Ethiopians still 
depend on traditional medicine. Since the knowledge and use of plants for medicinal purposes is an essential part of many ethnic rural cultures in Ethiopia, cultural acceptability (Bekele, 2007; Bekalo et al., 2009) and efficiency of traditional medicines against certain types of disease as compared to modern medicine can be the other reasons(Omoruyi et al., 2012).

Popular knowledge of plants used by humans is based on thousands of years of experience, careful observations and trial and error experiments (Martin, 1995). By "trial and error", people learned how to recognize and use plants, including those with a magic-religious function (Camejo-Rodrigues et al., 2003). Almost all traditional medical preparations in Ethiopia (95\%) are of plant origin (Wubetu et al., 2018). Medicinal plants are the basis for the development of new drugs and the survival of mankind as well as their livestock.

The knowledge and use of plants for medicinal purposes is an integral part of many ethnic rural cultures in Ethiopia (Bekalo et al. 2009). Due to the existence of diverse cultures, beliefs and languages, the expectation of a wide variety of traditional knowledge and uses of medicinal plant species in the country are high.

The ancient knowledge concerning the use of traditional medicinal plants is maintained by traditional healers. In the rural part of Ethiopia, which is much of the knowledge on traditional medicinal plants in most cases available, either the knowledge from herbalists is passed mysteriously from one generation to the next orally (Jansen, 1981) or their descendants inherit the medico-spiritual manuscripts (Tilahun and Giday, 2007).

\subsection{Statement of the Problem}

Ethiopia is believed to be home for about 6500 species of higher plants, with approximately $12 \%$ endemic (UNEP, 1995; Bekele, 2007; Mesfin et al., 2014). Medicinal plants comprise one of the important components of the vegetation. They play a key role in the development and advancement of modern studies by serving as a starting point for the development of innovations in drugs (Balick and Cox, 1996). According to Tora and Heliso (2017), there are 600 species of medicinal plants constituting a little over 10 percent of Ethiopia's vascular flora. As compared to the other areas, the greater concentration of medicinal plants is found in the south and southwestern parts of the country following the presence of more biological and cultural diversity (Belayneh et al. 2012). However, irrespective of their great concentration in the past these plants are currently facing a problem of continuity and sustainability. The current loss of medicinal plants can be due to lack of proper documentation of indigenous knowledge on medicinal plants (Lulekal et al., 2008; Giday et al., 2009; Regassa, 2013), increase of modern education, which has made the younger generation to undervalue the local indigenous knowledge on medicinal plants (potential acculturation) (Zerabruk and Yirga, 2012; Lulekal et al., 2008). According to Bekele (2007), the issue of medicinal plant conservation in Ethiopia calls for study and documentation before the accelerated ecological and cultural transformation distort the physical entities and the associated knowledge base. Like many other parts of Ethiopia, people in the Southern Nations, Nationalities and Peoples' Region (SNNPR) do have indigenous knowledge on the preparation and use of traditional medicinal plants. Even though different studies have been conducted to document medicinal plants in different areas of SNNPR separately, there is no previous review work which summarizes the medicinal plants and the associated indigenous knowledge at the regional level (at SNNPR region as a whole or in large scale). Also, there is no previous review work that prioritizes the factors that affect medicinal plants at the regional level (including threatened medicinal plants).

Prioritizing the factors that affect medicinal plants and identifying threatened medicinal plants could be useful in giving conservation and management priority for identified threatened medicinal plant species (Mesfin et al., 2014).

\subsection{The Purpose of the Article}

$\checkmark$ To review growth forms, habitat, method of remedy preparation and administration and marketability of medicinal plants in SNNPR

$\checkmark$ To prioritize the factors that affect medicinal plants in most areas (in most reviewed areas) of SNNPR

$\checkmark$ To identify plant species those require special attention in future conservation and management efforts in the region.

\section{Growth Forms}

The majority of medicinal plants used in Amaro (Mesfin et al., 2014), Bench (Giday et al., 2009), Cheha (Bizuayehu and Assefa, 2017), Dawro (Andarge et al., 2015), Kembatta (Maryo et al., 2015), South Omo (Tolossa et al., 2013), Mirab-Badwacho (Temam and Dillo, 2016) and Lowlands of Konta (Bekalo et al., 2009) areas of SNNPR are herbs (see Figure 1A). The high use of herbs as medicinal plants as compared to the other growth forms in these areas can be due their better abundance (availability) (Giday et al., 2009; Andarge et al., 
2015). It may also due to the higher chance of obtaining pharmacologically active compounds (like alkaloids and flavonoids) in herbs as compared to woody plant forms (Thomas et al., 2009). In addition to availability and a chance of obtaining pharmacologically active compounds, socio-cultural beliefs and practices of the healers may contribute to the high use of herbs. The common use of herbs is also reported in studies carried out elsewhere in Ethiopia (Yineger et al., 2007; Teklehaymanot et al., 2007; Giday et al., 2003 ) and other parts of the world (Tabuti et al., 2003; Muthu et al., 2006).

The trend of using more of herbaceous plants in most areas SNNPR can be seen as a benefit because it is easier to cultivate herbs when they are in short supply and availability of more herbaceous plant species as compared to trees (Bekalo et al., 2009).

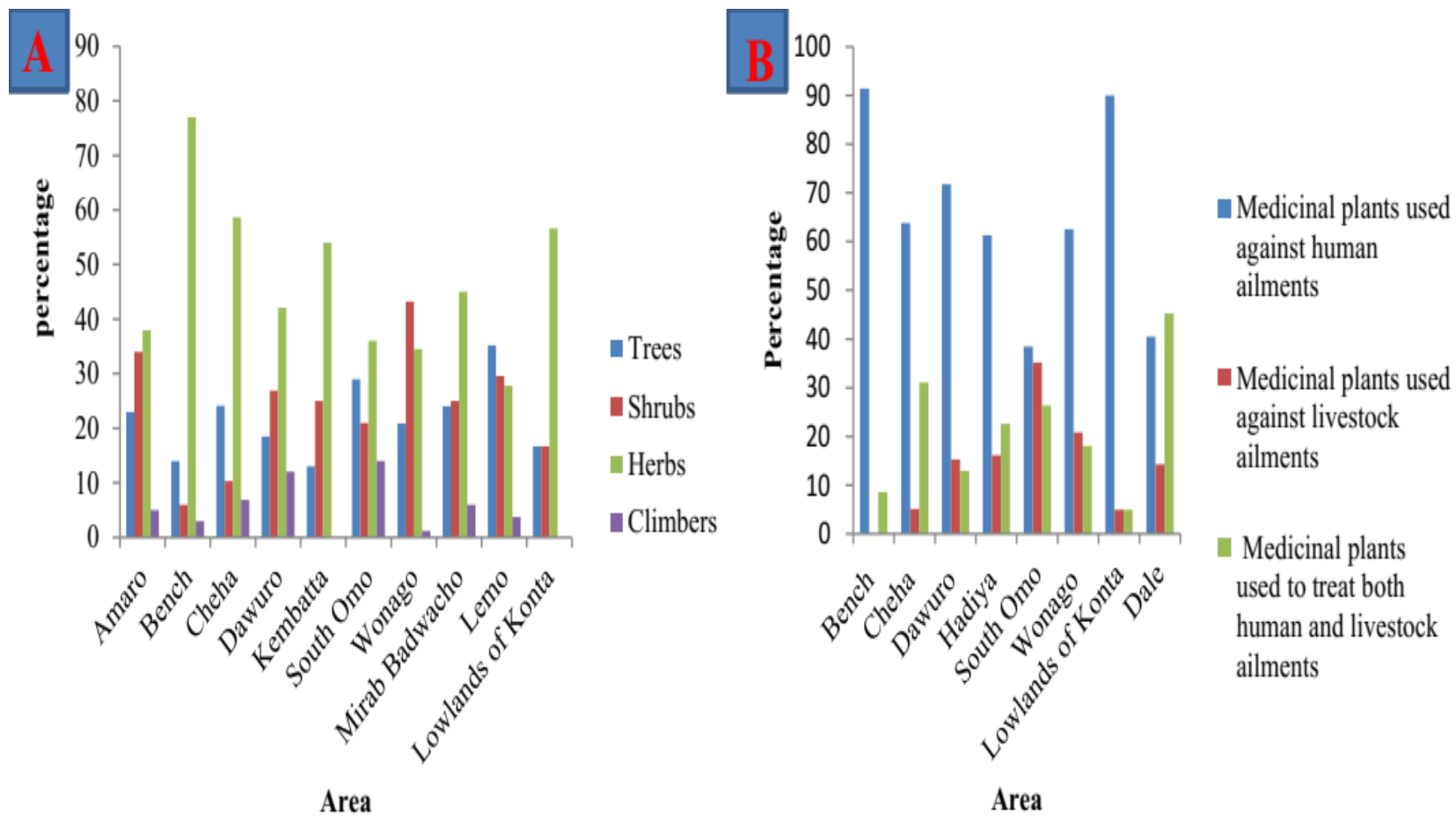

Figure 1. (A) Growth forms of medicinal plants (Mesfin et al., 2014; Giday et al., 2009; Bizuayehu and Assefa, 2017; Andarge et al., 2015; Maryo et al., 2015; Tolossa et al., 2013; Mesfin et al., 2009; Temam and Dillo, 2016; Kebebew and Mohamed, 2017; Bekalo et al., 2009), (B) Proportion of medicinal plants used to treat human, livestock and both human and livestock ailments in the reviewed areas of SNNPR (Giday et al., 2009; Bizuayehu and Assefa, 2017; Andarge et al., 2015; Agisho et al., 2014; Tolossa et al., 2013; Mesfin et al., 2009; Bekalo et al., 2009; Kewessa et al., 2015)

\section{Habitat (Degree of Management)}

The bulk of medicinal plants in most of the reviewed areas of SNNPR (Amaro, Bench, Dawro, Kembatta, Wonago, Mirab Badwacho and Lowlands of Konta) with the exceptions of Cheha and Lemo, are harvested from wild (see Figure 2). This implies that the majority of plants of medical importance are not yet cultivated by traditional healers. Thus, the high dependence on medicinal plants which are harvested from the wild habitats may have a considerable impact on the future availability of these resources and it will likely account for their vulnerability to being overexploited. Whereas, the exceptional case in the two areas (Cheha and Lemo) showed that the practitioners (traditional healers) have enhanced attitude on the importance of ex-situ conservation (since the society in these two areas depending on the home-garden source or cultivated rather than wild or natural environment to obtain the medicinal plants) in having long-lasting advantage on the sustainability of medicinal plants. 


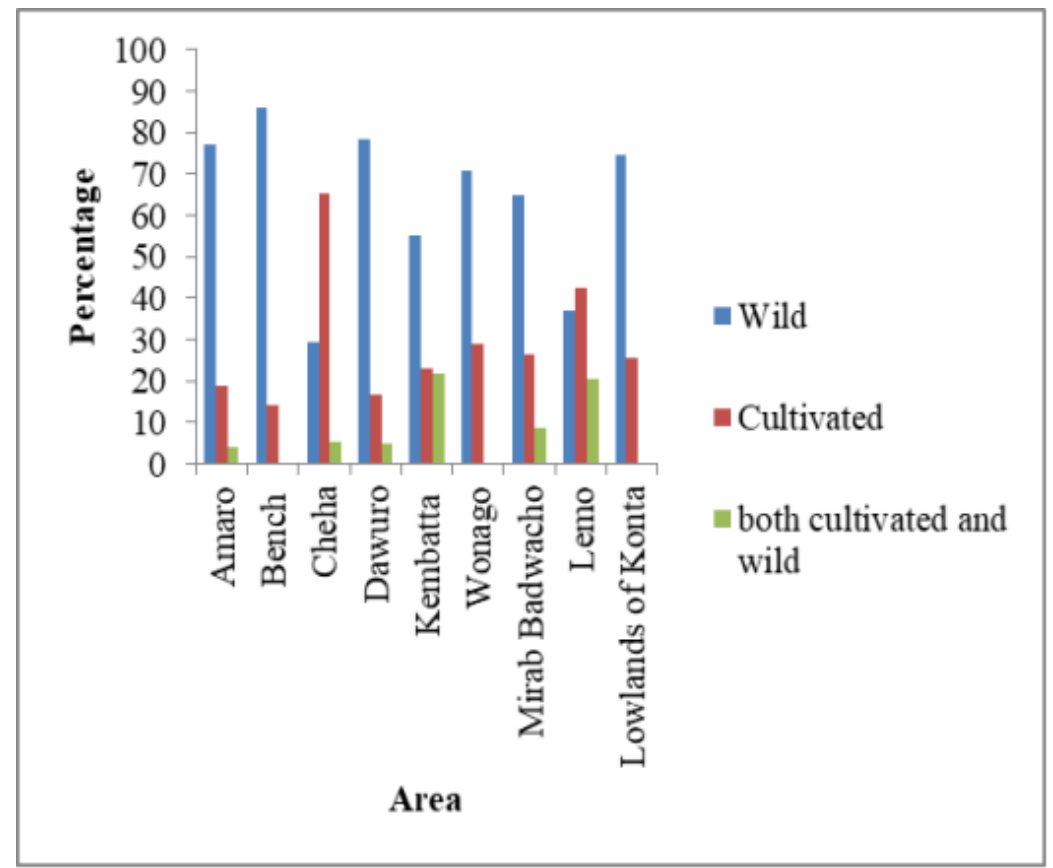

Figure 2. Habitat (degree of management) of medicinal plants (Andarge et al., 2015; Bekalo et al., 2009;

Bizuayehu and Assefa, 2017; Giday et al., 2009; Kebebew and Mohamed, 2017; Maryo et al., 2015; Mesfin et al., 2009; Mesfin et al., 2014;Temam and Dillo, 2016)

\section{Ailments Treated}

In SNNPR, the reported medicinal plant species were used to treat ailments of human, livestock or both. However, a majority of the reported medicinal plants were used to treat human ailments only (see Figure 1B).

\section{Remedy Preparation}

\subsection{Plant Parts Used in the Preparation of Remedies}

Leaves, seeds, roots, flowers, stem bark, and fruits are the identified plant parts that are used in the preparation of remedies. However, leaves are the majorly used plant part in preparation of remedies in most of the reviewed areas (Dawuro (Andarge et al., 2015), Bench Maji (Giday et al., 2009), Cheha (Bizuayehu and Assefa, 2017), Kembatta (Maryo et al., 2015), Amaro (Mesfin et al., 2014), Lemo (Kebebew and Mohamed, 2017), Lowlands of Konta (Bekalo et al., 2009), Mirab-Badwacho (Temam and Dillo, 2016) and Wolaita (Tora and Heliso, 2017)) of SNNPR.

Relative easiness of finding because of better accessibility during field collection (Giday et al., 2009), easiness of preparation (Gazzaneo et al. 2005) as well as effectiveness due to bioactive components (Chekole, 2017; Mesfin et al., 2014) can be the reasons for a major utilization of leaves as compared to other plant parts, in the preparation of remedies in most of the areas of SNNPR.

Use of leaves (appreciable amount of leaves) in the preparation of remedies in most of the areas can be considered as an opportunity for the long life of the plant. Since it may reduce the chance of plant diversity declination (plants in which their leaves are harvested have a low level of wilting unlike that of root and stem harvest) (Andarge et al., 2015; Bizuayehu and Assefa, 2017). Thus, it can be said that areas in which plant roots were primarily used as a major plant part in the preparation of remedies are in question of sustainable use of medicinal plant species.

\subsection{The Condition of Plant Materials Used in the Preparation of Remedies}

Like in many other parts of Ethiopia, fresh and dry plant materials are used in the preparation of remedies in the SNNPR region. However, fresh (newly harvested) plant materials are the most utilized plant materials in the preparation of remedies in the region (Giday et al., 2009; Mesfin et al., 2014; Kewessa et al., 2015; Andarge et al., 2015; Maryo et al., 2015; Bekalo et al., 2009). Availability of plant materials in the people vicinity that can be picked at any time, an attempt not to lose volatile oils, the concentrations of which might deteriorate when dry (Mesfin et al., 2014), can be the reasons for fresh materials are majorly utilized in the remedy preparation. Also, 
it can be due to believing that fresh preparations are effective in healing ailments (Maryo et al., 2015).

\subsection{Method of Remedy Preparation and Mode of Administration}

Decoction (Giday et al., 2009; Mesfin et al., 2014; Agisho et al., 2014; Maryo et al., 2015; Bekalo et al., 2009; Mesfin et al., 2009; Bizuayehu and Assefa, 2017),concoction (Mesfin et al., 2014; Bizuayehu and Assefa, 2017; Agisho et al., 2014; Bekalo et al., 2009; Tolossa et al., 2013; Mesfin et al., 2009), powder (Giday et al., 2009; Bizuayehu and Assefa, 2017; Mesfin et al., 2009; Maryo et al., 2015), infusion and juice (Giday et al., 2009; Mesfin et al., 2014),crushing (Mesfin et al., 2014; Bizuayehu and Assefa, 2017; Kewessa et al., 2015; Agisho et al., 2014; Maryo et al., 2015; Bekalo et al., 2009; Mesfin et al., 2009), paste (Giday et al., 2009; Mesfin et al., 2014; Tolossa et al., 2013), boiling (Kewessa et al., 2015), squeezing (Kewessa et al., 2015; Maryo et al., 2015), burning (Kewessa et al., 2015), filtrate (a liquid from which insoluble impurities have been removed)(Tolossa et al., 2013) and unprocessed are the identified methods of remedy preparation in SNNPR region.

In the preparation of remedies, medicinal plants can be used with or without the use of diluents (Giday et al., 2009). Local drinks (Tolossa et al., 2013), water, boiled coffee, milk, human saliva (Giday et al., 2009) and butter (Maryo et al., 2015) are the identified diluents that are used in the preparation of remedies in the region.

Different criteria can be used to select diluents that can be used in the preparation of remedy for a particular ailment. According to Giday et al. (2009), availability is one of the criteria that healers may use in the selection of diluents. Diluents may serve as a vehicle to administer the remedies (Etana, 2010) and may also enhance the efficacy and healing conditions.

Applications through mouth (orally), ear (auricular), nose, (nasally), eyes (trough eyes) and skin are the identified routes of administration of traditional medicines in SNNPR region. Selection of the route of administration of traditional medicines may be dependent on the ailment being treated.

According to Giday et al. (2009), the dominance of one route of administration on the others can be an indication for the high occurrence of certain ailments in an area (for example in an area if most remedies are applied topically on the skin it can be an indication to the high occurrence of skin-related ailments in that area).

\section{Marketability}

The majority of the medicinal plant species used in the traditional medicines were not available for sale at local markets in SNNPR (Giday et al., 2009; Maryo et al., 2015; Bekalo et al., 2009). The harvest of medicinal plants from the immediate environment in which medicinal plant species are abundantly found can be why most medicinal plants were not available for sale at the local markets (Giday et al., 2009; Mesfin et al., 2014). Among those which are available for sale in the local markets, some of them are marketed merely for their medicinal value and the rest for other use values (e.g. foods or spices).

Twelve medicinal plant species are identified and sold in the market for their medicinal value: Acacia abyssinica Hochst., Artemisia afra Jacq.ex willd., Aframomum corrorima (Braun) Jansen., Amaranthus caudatus seed L., Artemisia absinthium L., Brassica juncea, Echinops kebericho Mesfin., Hagenia abyssinica (Bruce) J.F.Gmelin, Ipomoea batatas (L.) Lam., Lepidium sativum L., Ocimum basilicum var. thyrsiflorum (L.) Benth., and Securidaca longipedunculata Fresen.. On the other hand, Allium cepa L., Allium sativum L., Carica papaya L., Citrus aurantiifolia (Christm.) Swingle, Cymbopogon citratus (DC.) Stapf., Nigella sativa L., Plectranthus ornatus Codd, and Ruta chalepensis L. are the medicinal plant species that are marketed for other use-values (as spices or fruits).

\section{Threats to Medicinal Plants}

A threat is a status or the position of a species which determines whether it will survive or be extinct in the future (Bizuayehu and Assefa, 2017). Various human-induced and natural factors can threaten the survival of many medicinal plant species. However, the degree of threats varies from place to place and species to species (Agisho et al., 2014).

In the reviewed areas, numerous threats to medicinal plant species are identified by different researchers (Bekalo et al., 2009; Mesfin et al., 2009, Agisho et al., 2014; Mesfin et al., 2014; Kewessa et al., 2015; Maryo et al., 2015; Bizuayehu and Assefa, 2017). According to the result of this review, the major threat to medicinal plants in the reviewed areas of SNPPR is agricultural land expansion (it is mentioned as the first threat to medicinal plants in four areas out of eight) (see Table 1) followed by deforestation. Other threats claimed to medicinal plants in the areas include deforestation, fire, firewood, charcoal production, overgrazing, drought, trade, climate change, urbanization, construction, overutilization, timber production, and home use.

Olea europaea L. subsp. cuspidata (Mesfin et al., 2014), Prunus Africana (Hook.f.) Kalkm. (Giday et al., 2009), 
Echinops kebericho Mesfin, Croton macrostachys Del., Cordia Africana Lam., Dodonaea angustifolia L.f., Hagenia abyssinica (Bruce) J.F.Gmelin, Withania somnifera (L.) Dunal (Bizuayehu and Assefa, 2017) and Ficus spp (Kebebew and Mohamed, 2017) are the identified medicinal plant species which are highly affected by the threats.

Table 1. Threats to medicinal plants in SNNPR

\begin{tabular}{|c|c|c|c|c|c|c|c|c|c|c|c|c|c|c|c|c|}
\hline Area & Df & $\mathbf{A e}$ & $\mathbf{F}$ & Fw & $\mathbf{C p}$ & Fw\&Cp & $\mathbf{O g}$ & D & $\operatorname{Tr}$ & Ce & Urb & Con & $\mathrm{Ou}$ & $\mathbf{T p}$ & Hu & Source \\
\hline Amaro & 1 & 2 & 3 & & & 4 & 5 & 6 & & & & & & & & Mesfn et al., 2014 \\
\hline \multirow[t]{2}{*}{ Cheha } & 2 & 1 & & & & 2 & & & & & & & 4 & & & Bizuayehu and \\
\hline & & & & & & & & & & & & & & & & Assefa, 2017 \\
\hline Hadiya & & 1 & & 2 & 3 & & 5 & 7 & 6 & & & & & & 4 & Agisho et al., 2014 \\
\hline Kembatta & 1 & 2 & & 6 & & & 3 & & & 5 & & & 4 & & & Maryo et al., 2015 \\
\hline Wonago & & 1 & & 2 & & & 3 & 4 & & & 5 & 6 & & & & Mesfin et al., 2009 \\
\hline Dale & & 1 & & 5 & & & & 4 & & & & 2 & & 3 & & Kewessa et al., 2015 \\
\hline Lowlands of & & & 2 & 1 & 4 & & & & & & & 3 & & & & Bekalo et al., 2009 \\
\hline Konta & & & & & & & & & & & & & & & & \\
\hline
\end{tabular}

Where, $\mathrm{Df}=$ Deforestation, $\mathrm{Ae}=$ Agricultural land expansion, $\mathrm{F}=\mathrm{Fire}, \mathrm{Fw}=$ Firewood, $\mathrm{Cp}=$ Charcoal production, $\mathrm{Og}=\mathrm{Overgrazing}, \mathrm{D}=$ Drought, $\mathrm{Tr}=\mathrm{Trade}, \mathrm{Cc}=$ Climate change, Urb=Urbanization, $\mathrm{Con}=$ Construction, Ou= Overutilization, $\mathrm{T} p=\mathrm{Timber}$ production, $\mathrm{Hu}=\mathrm{Home}$ use

$1=$ First threat, $2=$ second threat, $3=$ Third threat, $4=$ Fourth threat, $5=$ Fifth threat, $6=$ Sixth threat, $7=$ Seventh threat

\section{Medicinal Plant Knowledge Secrecy and Way of Transfer}

The secrecy of traditional medical practice is a common phenomenon in the SNNPR. (Andarge et al., 2015; Giday et al., 2009; Agisho et al., 2014; Mesfin et al., 2014; Tora and Heliso, 2017; Mesfin et al., 2009). This secrecy is also found in other parts of the country and worldwide (Yineger and Yewhalaw, 2007). The presence of a strong belief that medicinal plants will lose their healing power or die if other people know them (Agisho et al., 2014) and the fear of losing societal recognition and reputation which traditional healers have earned due to their knowledge (Mesfin et al., 2014) can be the major reasons why traditional healers kept their knowledge secret on the use of medicinal plants.

Traditional healers in SNNPR transfer their indigenous knowledge orally to the family members (to selected family members to keep up the secrecy) usually to their sons (Giday et al., 2009; Mesfn et al., 2014; Maryo et al., 2015; Tora and Heliso, 2017).

\section{Conclusions}

This review shows that herbs are the most utilized life forms in the preparation of remedies in SNNPR. This trend of using more of herbaceous plants can be seen as a benefit due to ease of cultivating herbs when they are in short supply and due to their better availability as compared to the other growth forms. Utilization of leaves in most areas of the region as a major consumable medicinal plant part should be kept because it may reduce the chance of risk of depletion of medicinal plant in the region. Harvest of considerable amounts of plants from wild in most areas may introduce a risk of reduction in the wild. So people and other responsible stakeholders should work on a better achievement of ex situ conservation. This will help the society to develop the habit of cultivating plant resources which ensure medicinal plants and indigenous knowledge continuity for future generations. Majority of the reported medicinal plants were used to treat human ailments only. Thus, further studies that give emphasis on medicinal plants that used to treat livestock ailments should be conducted. People should also develop the habit of drying and storing medicines (for those medicines that can be utilized in the dry and fresh form; i.e. storage may also depend on the shelf-life of the material as well as the availability of proper storage facility) for future uses in order to reduce the risk of threat on medicinal plants. Agricultural land expansion and deforestation are the major threats to medicinal plants that require special attention in SNNPR. Croton macrostachys, Cordia Africana, Dodonaea angustifolia, Echinops kebericho, Ficus spp, H. abyssinica, Olea europaea subsp. cuspidata, Prunus africana, and, Withania somnifera are plant species which require conservation and management priority in the region.

\section{Acknowledgments}

I would like to acknowledge Haramaya University for covering the publication fee of this review paper. Also, I would like to thank Mrs. Feven Mulugeta and Mrs. Tsetita Tesfaye for their unreserved support. Finally, Special 
thanks will go to all who contributed in manuscript preparation.

\section{References}

Abebe, D. (1986). Traditional medicine in Ethiopia. The attempt being made to promote it for effective and better utilization. SINET: Ethiopian Journal of Science, 9, 61-69.

Addis, G., Abebe, D., \& Urga, K. (2001). A survey of traditional medicine in Shirka District, Arsi Zone, Ethiopia. Ethiopian Pharmaceutical Journal, 19, 30-47.

Agisho, H., Osie, M., \& Lambore, Ts. (2014).Traditional medicinal plants utilization, management, and threats in Hadiya Zone, Ethiopia. Journal of Medicinal Plants Studies, 2(2), 94-108.

Andarge, E., Shonga, A., Agize, M., \& Tora, A. (2015). Utilization and conservation of medicinal plants and their associated Indigenous Knowledge (IK) in Dawuro Zone: An ethnobotanical approach. International Journal of Medicinal Plant Research, 4(3), 330-337.

Balemie, K., Kelbessa, E., \& Asfaw, Z. (2004). Indigenous Medicinal Utilization, Management, and Threats in Fentale Area, Eastern Shewa, Ethiopia. Ethiopian Journal of Biological Sciences, 3, 1-7.

Balick, M. J., \& Cox, P. A. (1996). Plants, People, and Culture. The Science of Ethnobotany. New York: Scientific American Library

Bekalo, T. H., Woodmatas, S. D., \& Woldemariam, Z. A. (2009). An ethnobotanical study of medicinal plants used by local people in the lowlands of Konta Special Woreda, southern nations, nationalities and peoples regional state, Ethiopia. Journal of Ethnobiology and Ethnomedicine, 5, 26. https://doi.org/10.1186/1746-4269-5-26

Bekele, E. (2007). Study on Actual Situation of Medicinal Plants in Ethiopia. Prepared for Japan Association for International Collaboration of Agriculture and Forestry, Addis Ababa, Ethiopia.

Belayneh, A., Asfaw, Z., Demissew, S., \& Bussa, N. (2012). Medicinal plants potential and use by pastoral and agropastoral communities in Erer Valley of BabileWereda, Eastern Ethiopia. Journal of Ethnobiology and Ethnomedicine, 8, 42. https://doi.org/10.1186/1746-4269-8-42

Birhan, Y. S., Kitaw, S. L., Alemayehu, Y. A., \& Mengesha, N. M. (2018). Ethnobotanical study of medicinal plants used to treat human diseases in EnarjEnawga District, East Gojjam Zone, Amhara Region, Ethiopia. SM Journal of Medicinal Plant Studies, 2(1), 1006.

Bizuayehu, B., \& Assefa, T. (2017). Ethnobotanical value of medicinal plant diversity in Cheha district, Guraghe zone, Southern Nations, Nationalities and Peoples (SNNPR) of Ethiopia. Journal of Medicinal Plants Research, 11(28), 445-454. https://doi.org/10.5897/JMPR2017.6356

Camejo-Rodrigues, J., Ascensao, L., Bonet, M. À., \& Valles, J. (2003). An ethnobotanical study of medicinal and aromatic plants in the Natural Park of Serra de São Mamede (Portugal). Journal of Ethnopharmacology, 89, 199-209. https://doi.org/10.1016/S0378-8741(03)00270-8

Chekole, G. (2017). Ethnobotanical study of medicinal plants used against human ailments in Gubalafto District, Northern Ethiopia. Journal of Ethnobiology and Ethnomedicine, 13, 55. https://doi.org/10.1186/s13002-017-0182-7

Etana, B. (2010). Ethnobotanical study of traditional medicinal plants of GomaWoreda, Jimma zone of Oromia region. Ethiopia: MSc Thesis, Addis Ababa University.

Farnsworth, N. (1994). Ethnopharmacology and drug development.Ethnobotany and the Search for New Drugs, Ciba Foundation Symposium 185 Chichester. John Wiley and Sons, UK Prance GT, pp. 42-59.

Friis, I., Demissew, S., \& van Breugel, P. (2011). Atlas of the potential vegetation of Ethiopia. Addis Ababa University Press and Shama Books.

Gazzaneo, L. R. S., Lucena, R. F. P., \& Albuquerque, U. P. (2005). Knowledge and use of medicinal plants by local specialists in a region of Atlantic Forest in the state of Pernambuco (Northeastern Brazil). Journal of Ethnobiology and Ethnomedicine, 1, 9. https://doi.org/10.1186/1746-4269-1-9

Giday, M., Asfaw, Z., Elmqvist, T., \& Woldu, Z. (2003) An ethnobotanical study of medicinal plants used by the Zay people in Ethiopia. Journal of Ethnopharmacology, 85, 43-52. https://doi.org/10.1016/S0378-8741(02)00359-8

Giday, M., Asfaw, Z., Woldu, Z., \& Teklehaymanot, T. (2009). Medicinal plant knowledge of the Bench ethnic group of Ethiopia: an ethnobotanical investigation. Journal of Ethnobiology and Ethnomedicine, 5(1), 34. 
https://doi.org/10.1186/1746-4269-5-34

Hishe, M., \& Asfaw, Z. (2015). Review on Ethnobotanical Studies on Traditional Medicinal Plants Used to Treat Livestock and Human Ailments in Tigray Region, Ethiopia. Advanced Journal of Biological Sciences Research, 3(002), 008-036.

Jansen, P. C. M. (1981). Spices, Condiments and Medicinal plants in Ethiopia: Their Taxonomic and agricultural significance. Centre for agricultural publishing and documentation. Wageningen, The Netherlands.

Kebebew, M., \& Mohamed, E. (2017). Indigenous knowledge on use of medicinal plants by indigenous people of Lemo District, Hadiya Zone, Southern Ethiopia. International Journal of Herbal Medicine, 5(4), 124-135.

Kelbessa E., Demissew S., Woldu Z., \& Edwards, S. (1992). Some threatened endemic plants of Ethiopia. In Edwards, S., \& Asfaw, Z. (Eds). The status of Some Plants in Parts of Tropical Africa (pp. 35-55), Botany 2000: NAPREC, Monograph Series No.2. Addis Ababa University.

Kewessa, G., Abebe, T., \& Demessie, A. (2015). Indigenous Knowledge on the Use and Management of Medicinal Trees and Shrubs in Dale District, Sidama Zone, Southern Ethiopia. Ethnobotany Research and Applications, 14, 171-182. http://dx.doi.org/10.17348/era.14.0.171-182.

Lambert, J. (2001). Ethiopia: traditional medicine and the bridge to better health. Knowledge and Learning Center.Africa Region. World Bank, Washington D.C, pp. 4.

Lulekal, E., Kelbessa, E., Bekele, T., \& Yineger, H. (2008). An ethnobotanical study of medicinal plants in ManaAngetu District, southeastern Ethiopia. Journal of Ethnobiology and Ethnomedicine, 4, 10. https://doi.org/10.1186/1746-4269-4-10

Martin, G. J. (1995). Ethnobotany.A methods manual. In: WWF for Nature International. Chapman \& Hall, London, UK. https://doi.org/10.1007/978-1-4615-2496-0

Maryo, M., Nemomissa, S., \& Bekele, T. (2015). An ethnobotanical study of medicinal plants of the Kembatta ethnic group in Enset-based agricultural landscape of KembattaTembaro (KT) Zone, Southern Ethiopia. Asian Journal of Plant Science and Research, 5(7), 42-61.

Mesfin, F., Demissew, S., \& Teklehaymanot, T. (2009). An ethnobotanical study of medicinal plants in WonagoWoreda, SNNPR, Ethiopia. Journal of Ethnobiology and Ethnomedicine, 5, 28. https://doi.org/10.1186/1746-4269-5-28

Mesfin, F., Seta, T., \& Assefa, A. (2014). An Ethnobotanical Study of Medicinal Plants in AmaroWoreda, Ethiopia. Ethnobotany Research and Applications, 12, 341-354. https://doi.org/10.17348/era.12.0.341-354

Muthu, C., Ayyanar, M., Raja, N., \& Ignacimuthu, S. (2006). Medicinal plants used by traditional healers in Kancheepuram District of Tamil Nadu, India. Journal of Ethnobiology and Ethnomedicine, 2, 43. https://doi.org/10.1186/1746-4269-2-43

Pankhurst, R. (2001). The status and availability of oral and written knowledge of traditional health care. In: Zewdu, M., Demissie, A. (Eds.), Conservation and Sustainable Use of Medicinal Plants in Ethiopia Proceeding of The National Workshop on Biodiversity Conservation and Sustainable Use of Medicinal Plants in Ethiopia (pp. 92-106). IBCR, AA, 28 April-01 May 1998.

Regassa, R. (2013). Assessment of indigenous knowledge of medicinal plant practice and mode of service delivery in Hawassa city, southern Ethiopia. Journal of Medicinal Plants Research, 7(9), 517-535.

Tabuti, J. R. S., Lye, K. A., \& Dhillion, S. S. (2003) Traditional herbal drugs of Bulamogi, Uganda: plants, use and administration. Journal of Ethnopharmacology, 88, 19-44. https://doi.org/10.1016/S0378-8741(03)00161-2

Teketay, D. (2001). Deforestation, wood famine, and environmental degradation in Ethiopia's highland ecosystems: urgent need for action. Forest Stewardship Council (FSC Africa), Kusama, Ghana. Northeast African Studies, 8, 53-76. https://doi.org/10.1353/nas.2005.0020

Teklehaymanot, T., Giday, M., Medhin, G., \& Mekonnen, Y. (2007). Knowledge and use of medicinal plants by people around DebreLibanos monstery of Ethiopia. Journal of Ethnopharmacology, 111, 271-283. https://doi.org/10.1016/j.jep.2006.11.019

Temam, T., \& Dillo, A. (2016). Ethnobotanical study of medicinal plants of Mirab-Badwacho district, Ethiopia. Journal of Bioscience and Biotechnology, 5(2), 151-158. 
Thomas, E., Vandebroek, I., Sanca, S., \& Van Damme, P. (2009). Cultural significance of medicinal plant families and species among the Quechua farmers in apillampampa, Bolivia. Journal of Ethnopharmacology, 122, 60-67. https://doi.org/10.1016/j.jep.2008.11.021

Tilahun, T., \& Giday, M. (2007). Ethnobotanical study of medicinal plants used by people in Zegie Peninsula, Northwestern Ethiopia. Journal of Ethnobiology and Ethnomedicine, 3, 12. https://doi.org/10.1186/1746-4269-3-12

Tolossa, K., Debela, Etana, Athanasiadou, S., Tolera, A., Ganga, G., \& Houdijk, J. G. M. (2013). Ethno-medicinal study of plants used for treatment of human and livestock ailments by traditional healers in South Omo, Southern Ethiopia. Journal of Ethnobiology and Ethnomedicine, 9, 32. https://doi.org/10.1186/1746-4269-9-32

Tora, A., \& Heliso, T. (2017). Assessment of the Indigenous Knowledge and Use of Traditional Medicinal Plants in Wolaita Zone, Southern Ethiopia. International Journal of Medicinal Plants and Natural Products (IJMPNP), 3(1), 16-22. http://dx.doi.org/10.20431/2454-7999.0301003

UNEP (United Nations Environment Program). (1995). Global Biodiversity Assessment. United Nations Environment Program, Nairobi, Kenya.

Wubetu, M., Sintayehu, M., Aeta, M., Reta, H., \& Derebe, D. (2018). Ethnobotany of Medicinal Plants used to Treat Various Mental illnesses in Ethiopia: A Systematic Review. Asian Journal of Plant Science and Research, 8(1), 9-33.

Yineger, H., \& Yewhalaw, D. (2007). Traditional medicinal plant knowledge and use by local healers in Sekoru District, Jimma Zone, Southwestern Ethiopia. Journal of Ethnobiology and Ethnomedicine, 3, 24. https://doi.org/10.1186/1746-4269-3-24

Yineger, H., Kelbessa, E., Bekele, T., \& Lulekal, E. (2007). Ethnoveterinary medicinal plants at Bale Mountains National Park, Ethiopia. Journal of Ethnopharmacology, 112, 55-70.

https://doi.org/10.1016/j.jep.2007.02.001

Yirga, G. (2010). Ethnobotanical Study of Medicinal Plants in and Around Alamata, Southern Tigray. Northern Ethiopia. Current Research Journal of Biological Sciences, 2, 338-344.

Zerabruk, S., \& Yirga, G. (2012). Traditional knowledge of medicinal plants in Gindeberet district, Western Ethiopia. South African Journal of Botany, 78, 165-169. https://doi.org/10.1016/j.sajb.2011.06.006

\section{Copyrights}

Copyright for this article is retained by the author(s), with first publication rights granted to the journal.

This is an open-access article distributed under the terms and conditions of the Creative Commons Attribution license (http://creativecommons.org/licenses/by/4.0/). 